\title{
Impact of the 2014 American Academy of Pediatrics Immunoprophylaxis Policy on the Rate, Severity, and Cost of Respiratory Syncytial Virus Hospitalizations among Preterm Infants
}

\author{
Leonard R. Krilov, MD $\quad$ Jaime Fergie, $\mathrm{MD}^{2} \quad$ Mitchell Goldstein, $\mathrm{MD}^{3} \quad$ Lance Brannman, $\mathrm{PhD}^{4}$
}

\author{
${ }^{1}$ Division of Pediatric Infectious Disease, Children's Medical Center, \\ NYU Winthrop Hospital, Mineola, New York \\ ${ }^{2}$ Department of Pediatric Infectious Disease, Driscoll Children's \\ Hospital, Corpus Christi, Texas \\ ${ }^{3}$ Division of Neonatal Medicine, Loma Linda University Children's \\ Hospital, Loma Linda, California \\ ${ }^{4}$ AstraZeneca, Gaithersburg, Maryland
}

Am J Perinatol 2020;37:174-183.
Address for correspondence Leonard R. Krilov, MD, Children's Medical Center, NYU Winthrop Hospital, 120 Mineola Boulevard, Suite 210, Mineola, NY 11501 (e-mail: Leonard.Krilov@nyulangone.org).

\author{
Abstract \\ Keywords \\ - gestational age \\ - hospitalization \\ - immunization, \\ passive \\ - infant \\ - infant, premature \\ - observational study \\ - practice guideline as \\ topic \\ - respiratory syncytial \\ viruses
}

Objective This study examined the rate, severity, and cost of respiratory syncytial virus (RSV) hospitalizations among preterm infants 29 to 34 weeks gestational age (wGA) versus term infants before and after a 2014 change in the American Academy of Pediatrics policy for RSV immunoprophylaxis.

Study Design Preterm (29-34 wGA) and term infants born from July 2011 to March 2017 and aged $<6$ months were identified in a U.S. commercial administrative claims database. RSV hospitalization (RSVH) rate ratios, severity, and costs were evaluated for the 2011 to 2014 and 2014 to 2017 RSV seasons. Postpolicy changes in RSVH risks for preterm versus term infants were assessed with difference-in-difference (DID) modeling to control for patient characteristics and temporal trends.

Results In the DID analysis, prematurity-associated RSVH risk was $55 \%$ greater in 2014 to 2017 versus 2011 to 2014 (relative risk $=1.55$, 95\% confidence interval: 1.10 2.17, $p=0.011$ ). RSVH severity increased among preterm infants after 2014 and was highest among those aged $<3$ months. Differences in mean RSVH costs for preterm infants in 2014 to 2017 versus 2011 to 2014 were not statistically significant.

Conclusion RSVH risk for preterm versus term infants increased after the policy change, confirming previous national analyses. RSVHs after the policy change were more severe, particularly among younger preterm infants.
Respiratory syncytial virus (RSV) is a common cause of lower respiratory tract infection and the leading cause of hospitalization among infants in the United States. ${ }^{1,2}$ Birth at $\leq 35$ weeks gestational age (wGA) is a strong risk factor for RSV hospitalization (RSVH), ${ }^{2}$ and young chronological age (CA) increases RSVH risk. From 1997 through 2006, an estimated 132,000 to 172,000 RSV-associated hospitalizations oc-

received

January 17, 2019 accepted after revision June 24, 2019 published online August 20, 2019
$10.1055 / \mathrm{s}-0039-1694008$ ISSN 0735-1631. curred annually among U.S. children aged $<5$ years, with those aged $<1$ year having the highest hospitalization rates. 1,3 Other conditions associated with increased RSVH risk include pulmonary disease (especially chronic lung disease of prematurity [CLDP]), hemodynamically significant congenital heart disease (CHD), immunodeficiency, and neuromuscular diseases. ${ }^{4}$ Preterm infants hospitalized for
Copyright $\odot 2020$ by Thieme Medical Publishers, Inc., 333 Seventh Avenue, New York, NY 10001, USA. Tel: +1(212) 584-4662.
License terms

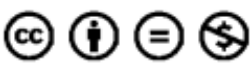


RSV disease have a high morbidity burden, including high rates of intensive care unit (ICU) admission and use of mechanical ventilation, ${ }^{5-7}$ particularly among younger infants. ${ }^{5,8,9}$

Although there are no recommended treatments or approved vaccines for RSV, passive immunization with the monoclonal antibody palivizumab has been shown to reduce hospitalizations due to $\mathrm{RSV}^{10}$ and is currently indicated for preventing serious lower respiratory tract disease caused by RSV in high-risk infants aged $<2$ years. ${ }^{11}$ Since the initial approval of palivizumab by the U.S. Food and Drug Administration in 1998, the American Academy of Pediatrics (AAP) Committee on Infectious Diseases (COID) has recommended immunoprophylaxis (IP) with palivizumab for infants at increased risk of RSV disease (summarized in -Table 1). ${ }^{4,12-17}$ In 2014, the AAP stated that palivizumab IP was no longer recommended for preterm infants $>29$ wGA without CLDP or CHD, ${ }^{4,18}$ asserting that the rates of RSVH among these infants were similar to those of term infants. ${ }^{19}$

The impact of the 2014 policy change on RSV IP and outcomes is not fully understood. The 2014 to 2017 RSV seasons were the first since 1998 during which otherwise healthy 29 to 34 wGA infants were ineligible for RSV IP according to the AAP policy. Several U.S. studies have demonstrated an increase in RSVH risk among infants 29 to 34 wGA and $<6$ months CA under the more restrictive recommendations. ${ }^{9,20-22}$ These findings would benefit from validation in other large datasets. In addition, the effect of the policy change on RSVH severity and costs has not been evaluated. The present study addresses these gaps by using a large U.S. administrative claims database to examine RSV IP use and the rates, severity, and costs associated with hospitalizations for RSV before and after the 2014 AAP policy change for 29 to $34 \mathrm{wGA}$ preterm infants versus term infants.

\section{Materials and Methods}

\section{Study Design and Data Source}

This was an observational retrospective cohort study conducted using administrative claims data from the Optum Research Database (ORD). The ORD contains medical and pharmacy claims with linked enrollment information covering 59.5 million lives from 1993 to the present and is geographically diverse across the United States. Medical claims in the ORD include diagnosis codes and procedure codes from the International Classification of Diseases, 9th/ 10th Revisions, Clinical Modification (ICD-9/10-CM); Current Procedural Terminology codes; Diagnosis Related Group codes; Healthcare Common Procedure Coding System codes; site of service codes; provider specialty codes; and paid amounts. Pharmacy claims in the ORD are for outpatient pharmacy services and include drug name, dosage form, drug strength, and fill date. Inpatient pharmacy claims are not captured in the ORD. Institutional Review Board approval or waiver of authorization was not required, as no identifiable protected health information was accessed during this study.

\section{Study Population}

The study included otherwise healthy 29 to 34 wGA preterm infants (the group affected by the 2014 AAP policy change) and $\geq 37$ wGA term infants (a group unaffected by the policy change). Included infants were required to have commercial health insurance; to have at least one medical claim with a

Table 1 American Academy of Pediatrics recommendations ${ }^{a}$ for respiratory syncytial virus immunoprophylaxis

\begin{tabular}{|c|c|c|c|c|}
\hline Risk factor & $1998^{b}$ & $2003^{c}$ & $2009^{d}$ & $2014^{e}$ \\
\hline$<29$ wGA & $\begin{array}{l}<12 \text { months of age } \\
\text { at season start }\end{array}$ & $\begin{array}{l}<12 \text { months of age } \\
\text { at season start }\end{array}$ & $\begin{array}{l}<12 \text { months of age } \\
\text { at season start }\end{array}$ & $\begin{array}{l}<12 \text { months of age } \\
\text { at season start; } \\
\text { no second season }\end{array}$ \\
\hline 29-31 wGA & $\begin{array}{l}<6 \text { months of age } \\
\text { at season start }\end{array}$ & $\begin{array}{l}<6 \text { months of age } \\
\text { at season start }\end{array}$ & $\begin{array}{l}<6 \text { months of age } \\
\text { at season start }\end{array}$ & Not recommended \\
\hline $32-35$ wGA & $\begin{array}{l}<6 \text { months of age } \\
\text { at season start with } \\
\text { additional risk }_{\text {factors }^{f}}\end{array}$ & $\begin{array}{l}<6 \text { months of age } \\
\text { at season start with } \\
\text { two of five risk } \\
\text { factors }\end{array}$ & $\begin{array}{l}32-34 \text { wGA and } \\
<3 \text { months of age } \\
\text { at season start with } \\
\text { one of two risk fac- } \\
\text { tors }{ }^{\text {h; }} \text { dose until } \\
3 \text { months CA }\end{array}$ & Not recommended \\
\hline
\end{tabular}

Abbreviations: CA, chronological age; wGA, weeks gestational age.

${ }^{a}$ Recommendations for infants with no other underlying reason for receiving RSV IP (i.e., chronic lung disease of prematurity or congenital heart disease).

${ }^{\mathrm{b}}$ American Academy of Pediatrics Committee on Infectious Diseases and Committee on Fetus and Newborn. ${ }^{12}$

${ }^{\mathrm{C}}$ Red Book: 2003 Report of the Committee on Infectious Diseases. 26th ed. ${ }^{14}$

${ }^{\mathrm{d}}$ Red Book: 2009 Report of the Committee on Infectious Diseases. 28th ed. ${ }^{16}$

${ }^{\mathrm{e}}$ American Academy of Pediatrics Committee on Infectious Diseases, American Academy of Pediatrics Bronchiolitis Guidelines Committee. ${ }^{4}$

fRisk factors include neurologic disease in very-low-birth-weight infants, number of young siblings, child care center attendance, exposure to tobacco smoke in the home, anticipated cardiac surgery, and distance to and availability of hospital care for severe respiratory illness.

${ }^{9}$ Risk factors include child care attendance, school-aged siblings, exposure to environmental air pollutants, congenital abnormalities of the airways, and severe neuromuscular disease.

${ }^{\text {h}}$ Risk factors include child care attendance and siblings $<5$ years of age. 
diagnosis code in any position for birth status and date of birth from July 1, 2011, through March 31, 2017 (study period); to have been discharged alive from their birth hospitalization during the study period; to have at least 1 day of continuous health plan enrollment with medical and pharmacy benefits after their index date (birth hospitalization discharge date plus 2 days); to have age, sex, geographic region, and insurance plan type recorded in the claims database; to be aged $<6$ months during the study period; and to have no evidence of other major health problems (CLDP, CHD, cystic fibrosis, immunodeficiency, congenital respiratory anomalies, neuromuscular disease, organ transplants, and other neuromuscular, immunological, or genetic conditions).

\section{Outcomes}

Study outcomes were assessed during the follow-up period, which began on the index date and continued until the earliest of the end of the study period, the end of the first 6 months of life, health plan disenrollment, or death. Outcomes were captured by RSV season (November 1 through March 31) during the follow-up period and stratified by wGA. As a supplemental analysis, outcomes were also stratified by CA at the time the outcome occurred $(<3$ or $3-<6$ months). RSV IP use was calculated as the proportion of infants with at least one medical or outpatient pharmacy claim for palivizumab at the specified CA. RSVH included hospitalizations coded as RSV infection, RSV pneumonia, and RSV bronchiolitis (ICD-9-CM codes 079.6, 466.11, and 480.1 or ICD-10-CM codes B974, J121, J205, and J210). Bronchiolitis hospitalizations (BHs) included those coded as RSV bronchiolitis and those coded as unspecified bronchiolitis (ICD-9CM code 466.19 or ICD-10-CM codes J218 and J219, if there was no evidence of RSV, influenza, bacterial pneumonia, or other viral pathogen within 3 days of the claim). RSVH and $\mathrm{BH}$ were not mutually exclusive; the percentage of hospitalized infants whose hospitalizations qualified as both RSVH and $\mathrm{BH}$ ranged from 95 to $98 \%$ in the RSVH group and from 70 to $82 \%$ in the $\mathrm{BH}$ group, depending on gestational age and RSV season. The rates of RSVH and $\mathrm{BH}$ were measured per 100 infants per RSV season (infant-seasons, analogous to personyears). Indicators of RSVH and BH severity included length of stay, ICU admission, and use of mechanical ventilation (including noninvasive approaches) during RSVH or $\mathrm{BH}$. The costs of RSVH and $\mathrm{BH}$ (combined health plan- and patient-paid amounts from the claims database) were calculated among infants with at least one applicable hospital stay and adjusted to 2015 US\$ using the medical care component of the Consumer Price Index. ${ }^{23}$

\section{Statistical Analyses}

Seasonal variations in RSV circulation and severity were accounted for using preterm/term rate ratios to compare hospitalization rates in the 2011 to 2014 (pre-policy change) and 2014 to 2017 (post-policy change) RSV seasons.

Multivariable difference-in-difference (DID) log binomial modeling was performed to investigate the differential effect of the AAP policy change on hospitalization risk for preterm infants versus term infants. DID analysis compares differences in outcomes before and after an intervention (in this case, the AAP policy change) between a group that is affected by the intervention (preterm infants) and a group that is unaffected by the intervention but exposed to the same background factors $^{24}$ (term infants). The DID expression for the post-2014 versus pre-2014 risk estimate was calculated as:

Hospitalization rate for preterm infants in 2014 to 2017/ hospitalization rate for preterm infants in 2011 to 2014

Hospitalization rate for term infants in 2014 to 2017/ hospitalization rate for term infants in 2011 to 2014 .

The ratios in the DID expression remove the influence of variables that are unrelated to the policy change but may vary over time. ${ }^{24}$ Examples of such variables are RSV season severity, trends in bronchiolitis admission practices, and the 2015 transition from ICD-9-CM to ICD-10-CM coding. Adjusted hospitalization rates derived from regression models that include WGA, time (pre- or post-policy change), CA, sex, and interaction of wGA and time as explanatory variables were used in the DID expression to control for possible differences between the groups being compared. $^{24}$

Other outcomes were compared among preterm and term infants for the 2011 to 2014 versus 2014 to 2017 RSV seasons using chi-square tests for categorical variables (RSVP IP use, ICU admission, and mechanical ventilation use) and $t$-tests for continuous variables (length of stay and costs). Statistical significance was defined as $p<0.05$. Statistical analyses were performed using SAS 9.4 (SAS Institute, Cary, NC).

\section{Results}

\section{Study Population}

Of $31,614,116$ patients with commercial insurance during the study period, 517,223 met the birth date, health plan enrollment, and age criteria; were discharged alive from the birth hospitalization; and had no missing demographic data. The final sample included 12,558 preterm infants and 323,216 term infants (-Fig. 1 ).

\section{RSV Immunoprophylaxis Use}

Outpatient RSV IP use among preterm infants (-Fig. 2) decreased significantly after the AAP policy change ( $p<0.001$ within each wGA cohort). The percentage of infants receiving at least one RSV IP dose while aged $<3$ months in 2011 to 2014 ranged from $23.6 \%$ (for 33-34 wGA infants) to $48.3 \%$ (for 29-30 wGA infants) (-Supplementary Table S1, available in the online version). In 2014 to 2017, these percentages fell to 0.2 and $6.3 \%$, respectively. Similarly, the percentage of preterm infants who received at least one RSV IP dose while aged 3 to $<6$ months (- Supplementary Table S1, available in the online version) ranged from $10.0 \%$ (for 33-34 wGA infants) to $69.8 \%$ (for 29-30 wGA infants) in 2011 to 2014 , but fell to 0.2 and $19.0 \%$, respectively, in 2014 to 2017. The proportion of term infants with RSV IP use was $<1 \%$ for all RSV seasons evaluated (data not shown). 


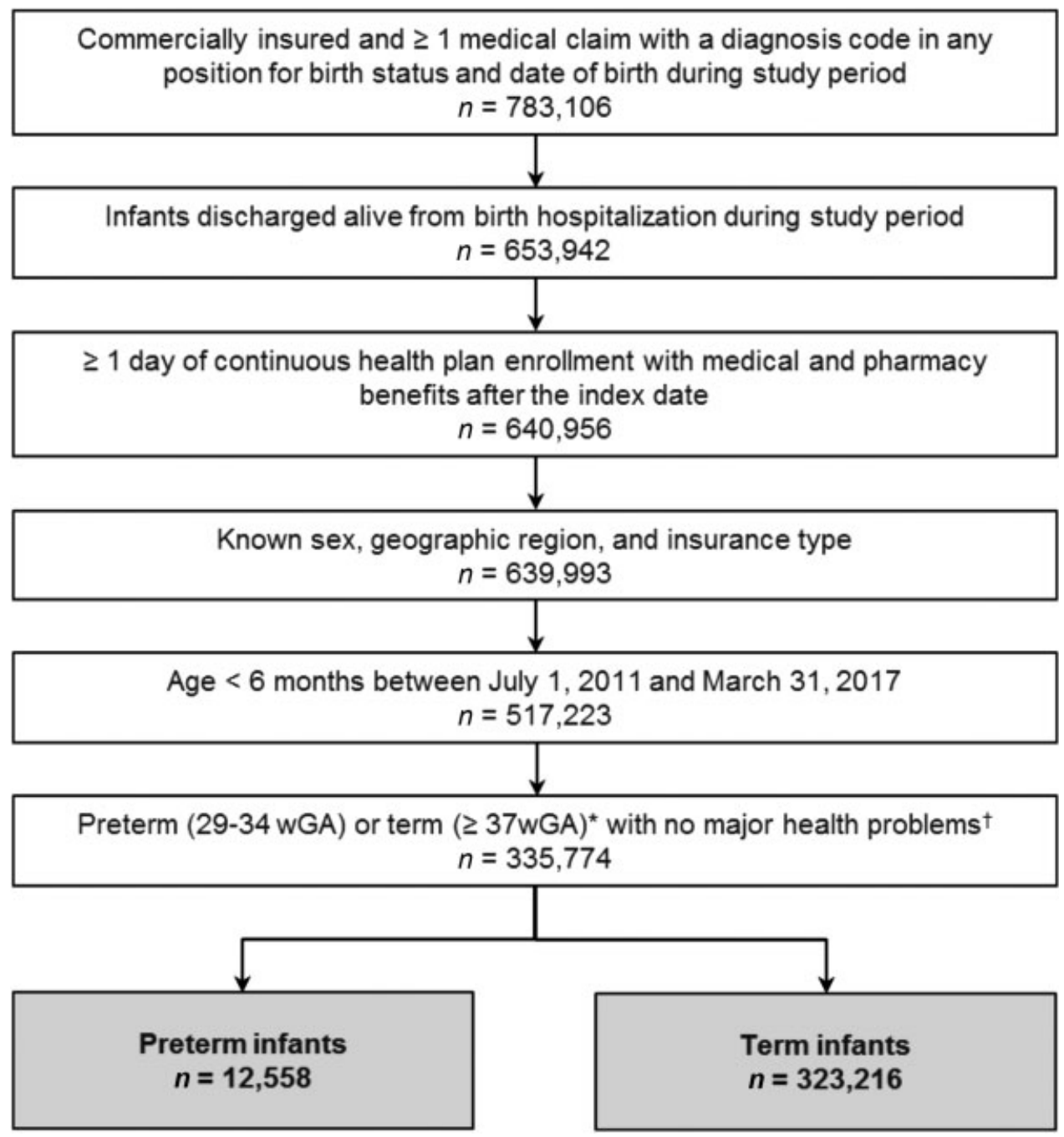

Fig. 1 Patient selection. wGA, weeks gestational age. *A large number of infants $(113,671)$ had an unknown gestational age and therefore were not eligible to be included in the final sample. ${ }^{\dagger}$ Major health problems (identified using International Classification of Diseases, 9th/10th Edition, Clinical Modification codes, Diagnosis Related Group codes, and Current Procedural Terminology codes) include chronic lung disease, congenital heart disease, cystic fibrosis, immunodeficiency, congenital respiratory anomalies, neuromuscular disease, organ transplants, and other neuromuscular, immunological, or genetic conditions.

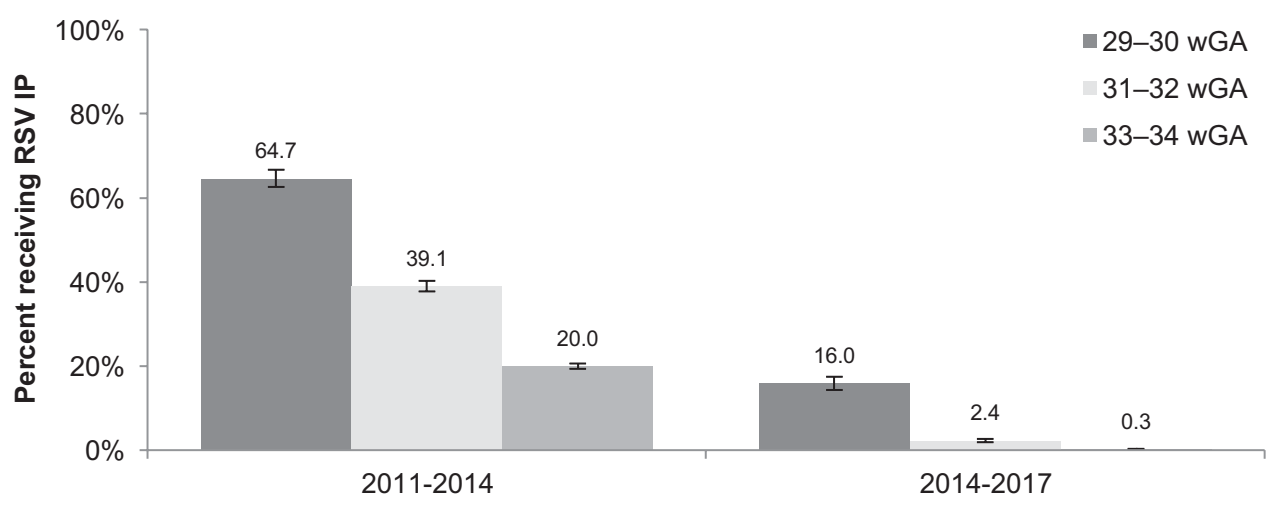

Fig. 2 Preterm infants receiving at least one outpatient dose of palivizumab by RSV season. Any claim for palivizumab was counted; doses were not required to be administered according to recommendations. RSV IP use among preterm infants within each gestational age group decreased in 2014 to 2017 compared with 2011 to 2014 ( $p<0.001$ for all). Error bars represent \pm 1 standard error. IP, immunoprophylaxis; RSV, respiratory syncytial virus; wGA, weeks gestational age. 


\section{Rates of RSV Hospitalization and Bronchiolitis Hospitalization}

Crude RSVH and BH rates (without adjustment for potential confounders) increased among preterm infants after the policy change. Unadjusted RSVH rates for preterm infants in the 2014 to 2017 versus 2011 to 2014 RSV seasons were 3.1 versus 2.1 per 100 infant-seasons $(p=0.022)$ ( $>$ Table 2 ). Unadjusted BH rates for preterm infants in the 2014 to 2017 versus 2011 to 2014 RSV seasons were 4.0 versus 2.5 per 100 infant-seasons $(p=0.001)$ (-Table 2 ). Infants aged $<3$ months had greater rates of both RSVH and $\mathrm{BH}$ than those aged 3 to $<6$ months (- Supplementary Table S2, available in the online version). Among term infants, the rates of RSVH and $\mathrm{BH}$ were unchanged in 2014 to 2017 compared with 2011 to 2014 ( $p>0.05$ for all CA groups) ( - Table 2 and - Supplementary Table \$2, available in the online version).

The rate ratios comparing unadjusted preterm infant hospitalization rates with unadjusted term infant hospitalization rates increased for RSVH and $\mathrm{BH}$ after the AAP policy change (-Table 3 ). From before to after the policy change, the rate ratios for preterm versus term infants increased from 1.9

Table 2 Unadjusted RSV hospitalization and bronchiolitis hospitalization rates for preterm and term infants

\begin{tabular}{|c|l|l|l|}
\hline \multirow{2}{*}{} & \multicolumn{2}{|l|}{$\begin{array}{l}\text { Hospitalizations per 100 } \\
\text { infant-seasons (95\% Cl) }\end{array}$} & \multirow{2}{*}{-Value } \\
\cline { 2 - 3 } & $2011-2014$ & $2014-2017$ & \\
\hline RSV hospitalization & 0.022 \\
\hline Preterm & $2.1(1.7-2.7)$ & $3.1(2.5-3.8)$ & 0.171 \\
\hline Term & $1.1(1.1-1.2)$ & $1.1(1.0-1.1)$ & 0.001 \\
\hline Bronchiolitis hospitalization \\
\hline Preterm & $2.5(2.0-3.1)$ & $4.0(3.3-4.8)$ & 0.018 \\
\hline Term & $1.3(1.2-1.3)$ & $1.2(1.2-1.3)$ & 0.618 \\
\hline
\end{tabular}

Abbreviations: $\mathrm{Cl}$, confidence interval; RSV, respiratory syncytial virus.

Table 3 Unadjusted RSV hospitalization and bronchiolitis hospitalization rate ratios for preterm infants versus term infants

\begin{tabular}{|c|c|c|}
\hline & $\begin{array}{l}\text { Rate ratio, } \\
\text { preterm } \\
\text { infants vs. term } \\
\text { infants }(95 \% \mathrm{Cl})\end{array}$ & $\begin{array}{l}p \text {-Value }{ }^{a} \text { for } \\
\text { pre- vs. } \\
\text { post-policy } \\
\text { change rate ratios }\end{array}$ \\
\hline \multicolumn{3}{|c|}{ RSV hospitalization } \\
\hline $2011-2014$ & $1.9(1.4-2.4)$ & \multirow[t]{2}{*}{0.011} \\
\hline $2014-2017$ & $2.9(2.3-3.7)$ & \\
\hline \multicolumn{3}{|c|}{ Bronchiolitis hospitalization } \\
\hline $2011-2014$ & $2.0(1.5-2.5)$ & \multirow[t]{2}{*}{0.001} \\
\hline $2014-2017$ & $3.3(2.6-4.0)$ & \\
\hline
\end{tabular}

Abbreviations: $\mathrm{Cl}$, confidence interval; RSV, respiratory syncytial virus. ${ }^{a}$-Values are for interaction of gestational age and time period (20112014 or 2014-2017), calculated using a difference-in-difference negative binomial model. to 2.9 for RSVH ( $p=0.011$ ) and from 2.0 to 3.3 for $\mathrm{BH}$ $(p=0.001)$. The rate ratios before and after the policy change for infants aged $<3$ months were similar to those for infants aged 3 to $<6$ months (- Supplementary Table S3, available in the online version). When examined by RSV season, hospitalization rate ratios before the policy change ranged from 1.2 to 2.8 for RSVH and from 1.3 to 2.6 for $\mathrm{BH}$ (-Fig. 3 ), compared with 2.1 to 3.7 for RSVH and 2.6 to 3.9 for BH after the policy change (-Fig. 3 ). The percentage of preterm infants in each RSV season receiving RSV IP was less following the AAP policy change (-Fig. 3 ).

Multivariable DID modeling of rate ratios with adjustment for patient characteristics (wGA, sex) revealed that the preterm RSVH risk relative to term infants increased significantly after the AAP policy change. The hospitalization risk associated with prematurity was $55 \%$ greater for $\mathrm{RSVH}$ (relative risk $=1.55,95 \%$ confidence interval $[\mathrm{CI}]$ : $1.11-$ $2.17, p=0.011$ ) and $63 \%$ greater for $\mathrm{BH}$ (relative risk $=1.63$, 95\% CI: $1.20-2.22, p=0.002$ ) in the 2014 to 2017 seasons compared with the 2011 to 2014 seasons.

\section{Severity of RSV Hospitalization and Bronchiolitis Hospitalization}

Mean length of stay for RSVH and BH (-Fig. 4A) among preterm infants was significantly greater after the AAP policy change. Mean (median) RSVH length of stay increased from 4.7 (4.0) days in 2011 to 2014 to 7.8 (5.5) days in 2014 to 2017 $(p=0.028)$. BH length of stay increased from 4.7 (4.0) to 7.5 (5.0) days $(p=0.015)$. Among term infants, mean length of stay for both RSVH and BH was unchanged in 2014 to 2017 compared with 2011 to 2014 (range: 4.4-4.5 days; $p>0.05$ for all CA groups). Preterm infants aged $<3$ months had the highest mean (median) length of stay overall: 5.4 (5.0) days pre-policy change versus 9.5 (6.0) days post-policy change $(p=0.062)$ for $\mathrm{RSVH}$, and 5.2 (4.0) days pre-policy change versus $9.6(6.0)$ days post-policy change $(p=0.022)$ for $\mathrm{BH}$ (-Supplementary Table \$4, available in the online version).

Admission to the ICU during RSVH and BH ( - Fig. 4B) was significantly more prevalent among preterm infants after the AAP policy change. In the 2014 to 2017 versus 2011 to 2014 RSV seasons, the proportions of ICU admissions among hospitalized preterm infants were 48.8 versus $26.6 \%$ for RSVH $(p=0.006)$ and 45.3 versus $25.3 \%$ for $\mathrm{BH}$ $(p=0.006)$. The proportions of term infants who were admitted to the ICU during RSVH and BH in 2014 to 2017 versus 2011 to 2014 were not significantly different: for RSVH, 26.8 versus 23.1\% ( $p=0.082$ ); for $\mathrm{BH}, 24.9$ versus $21.5 \%(p=0.080)$. Overall, ICU admission was most prevalent among preterm infants aged $<3$ months: $38.5 \%$ prepolicy change versus $62.3 \%$ post-policy change $(p=0.024)$ for RSVH, and $36.4 \%$ pre-policy change versus $63.9 \%$ postpolicy change ( $p=0.005$ ) for $\mathrm{BH}$ (-supplementary Table \$4, available in the online version).

The use of mechanical ventilation during RSVH and $\mathrm{BH}$ ( $=$ Fig. 4C) was numerically greater for preterm and term infants after the AAP policy change, but the differences between periods did not always reach statistical significance. In 2014 to 2017 versus 2011 to 2014, the proportions of 


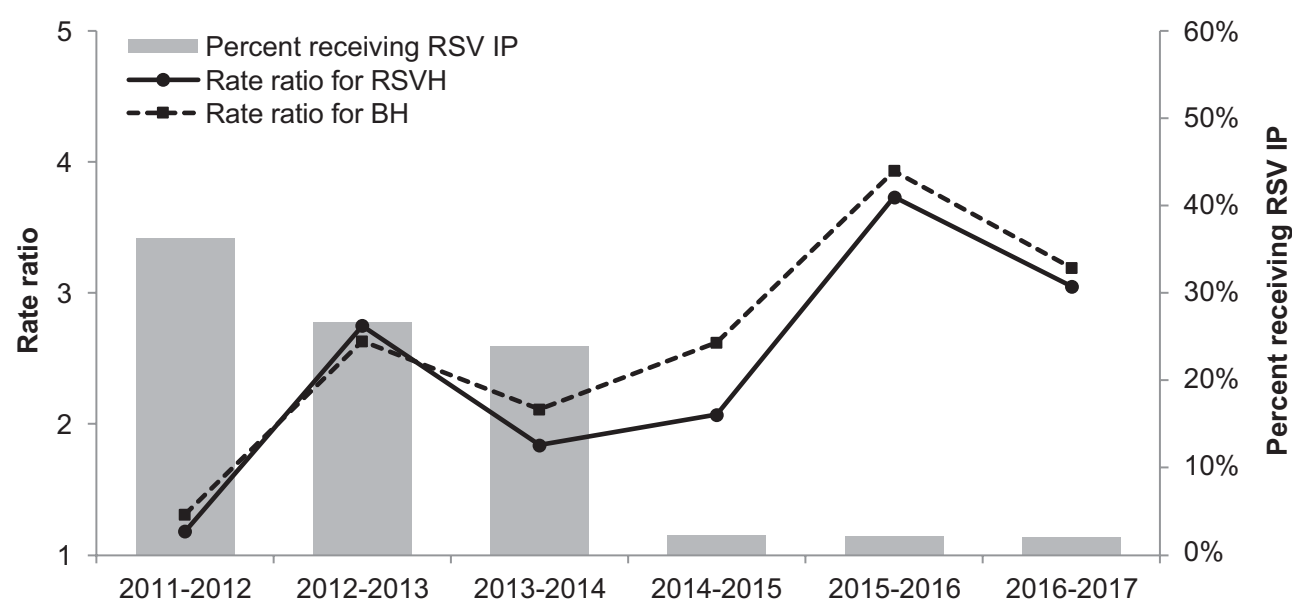

Fig. 3 Unadjusted RSV hospitalization and BH rate ratios by individual RSV season. The rate ratios indicate preterm infant risk relative to term infant risk. BH, bronchiolitis hospitalization; IP, immunoprophylaxis; RSV, respiratory syncytial virus; RSVH, RSV hospitalization; wGA, weeks gestational age.

infants who required mechanical ventilation during RSVH were 15.9 versus $6.3 \%(p=0.073)$ for preterm infants and 8.1 versus $4.3 \%(p=0.001)$ for term infants. The proportions requiring mechanical ventilation during $\mathrm{BH}$ were 15.1 versus $5.3 \%(p=0.039)$ for preterm infants and 7.6 versus $4.0 \%$ $(p<0.001)$ for term infants. Preterm infants aged $<3$ months had the highest prevalence of mechanical ventilation use overall: for RSVH, $10.3 \%$ pre-policy change versus $20.8 \%$ post-policy change $(p=0.178)$; for $\mathrm{BH}, 9.1 \%$ pre-policy change versus $23.0 \%$ post-policy change $(p=0.063)$ (-Supplementary Table S4, available in the online version).

\section{Costs of RSV Hospitalization and Bronchiolitis Hospitalization}

Mean hospitalization costs among preterm infants aged $<6$ months were numerically higher in the 2014 to 2017 RSV seasons compared with the 2011 to 2014 seasons, but these differences were not statistically significant $(p=0.089$ for RSVH and $p=0.070$ for BH; - Fig. 5). Mean hospitalization costs among term infants showed negligible changes in 2014 to 2017 versus 2011 to 2014 ( $p=0.148$ for RSVH and $p=0.126$ for $\mathrm{BH}$ ). Overall, the highest mean (standard deviation) hospitalization costs were found among preterm infants aged $<3$ months: $\$ 21,761(\$ 38,212)$ during the prepolicy change period versus $\$ 55,731(\$ 148,752)$ in the postpolicy change period $(p=0.116)$ for $\mathrm{RSVH}$, and $\$ 18,836$ $(\$ 33,804)$ pre-policy change versus $\$ 52,992(\$ 139,306)$ post-policy change $(p=0.070)$ for $\mathrm{BH}$ (-Supplementary Table S5, available in the online version). Median (interquartile range) hospitalization costs, presented in the footnote of -Fig. 5 and in -Supplementary Table S5 (available in the online version), showed similar patterns.

\section{Discussion}

This retrospective claims analysis of infants aged $<6$ months showed a significant decrease in outpatient use of RSV IP among 29 to 34 wGA preterm infants after the 2014 AAP policy change. This decreased use of RSV IP among preterm infants was concurrent with increased RSVH and $\mathrm{BH}$ risks compared with term infants; preterm/term rate ratios for RSVH and $\mathrm{BH}$ were greater in each post-2014 season relative to the 2011 to 2012 and 2013 to 2014 seasons. In addition, most RSVH and BH severity metrics increased in 2014 to 2017 compared with 2011 to 2014 among preterm infants-and were particularly high among preterm infants aged $<3$ months-while remaining similar among term infants. These findings suggest that the AAP policy change may have resulted in greater rates of RSVH among preterm infants and that these hospitalizations became more burdensome in terms of morbidity.

Our results are in line with those of previous analyses that found substantially decreased outpatient RSV IP use and increased RSVH risk among preterm infants after the AAP policy change. ${ }^{9,20-22}$ In single-center studies by Rajah et al and Blake et al, RSVH rates for preterm infants were significantly greater in post- versus pre-policy change RSV seasons. ${ }^{9,21}$ Similarly, administrative claims analyses utilizing a patient population comparable to ours from the Truven Health MarketScan database showed that RSVH risk among preterm infants increased significantly in the 2014 to 2015 season compared with the 2013 to 2014 season, ${ }^{20}$ and in the 2014 to 2016 seasons compared with the 2012 to 2014 seasons. $^{22}$

A few studies have not found increased RSVH rates after the AAP policy change; however, each of these has substantial methodological limitations, including failure to consider $\mathrm{CA}^{25}$ or specifically examine preterm infants, ${ }^{26}$ insufficient statistical power to detect clinically plausible differences in RSVH rates, ${ }^{26,27}$ and inclusion of premature infants who remained eligible for RSV IP in the 2014 to 2015 season per Texas Medicaid policies. ${ }^{25,28,29}$

Importantly, our DID analysis-which isolated the impact of the AAP policy change by adjusting for other temporal factors-showed that the increased RSVH risk associated with preterm status increased further under the more restrictive RSV IP recommendations, corroborating the results of a similar analysis by Goldstein et al. ${ }^{22}$ Thus, 

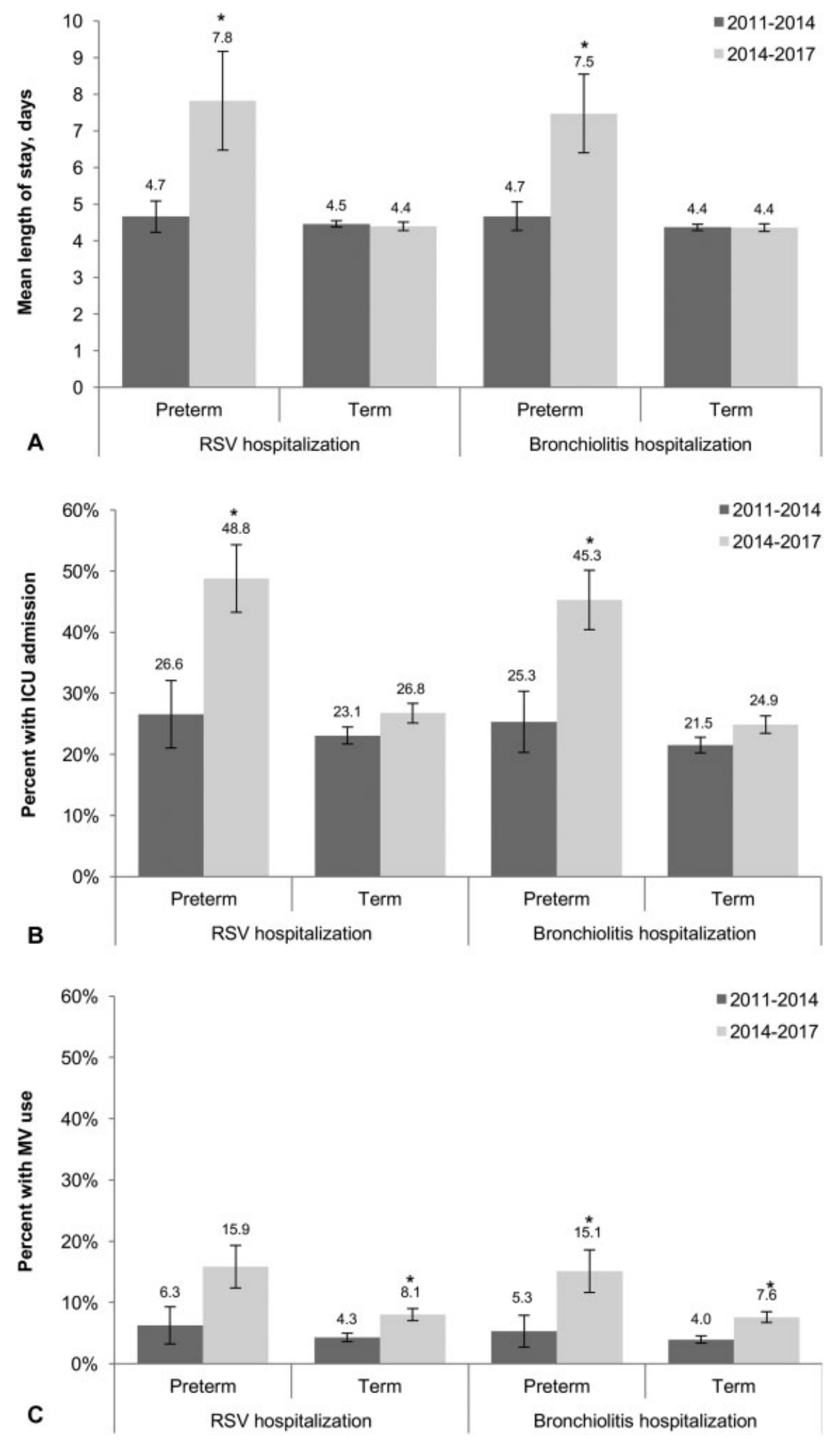

Fig. 4 Severity indicators for RSV hospitalization and bronchiolitis hospitalization. (A) Length of hospital stay. (B) ICU admission during hospitalization. (C) MV use during hospitalization. Error bars represent \pm 1 standard error. ICU, intensive care unit; MV, mechanical ventilation. ${ }^{*} p<0.05$ for differences between time periods.

contrary to the assertion that RSVH rates are similar among preterm infants and term infants, ${ }^{19}$ the predominant evidence confirms that preterm infants are at greater risk of
RSVH compared with term infants $\mathrm{s}^{2,3,5,8,30,31}$ and indicates that this risk disparity has worsened since the AAP policy change. 


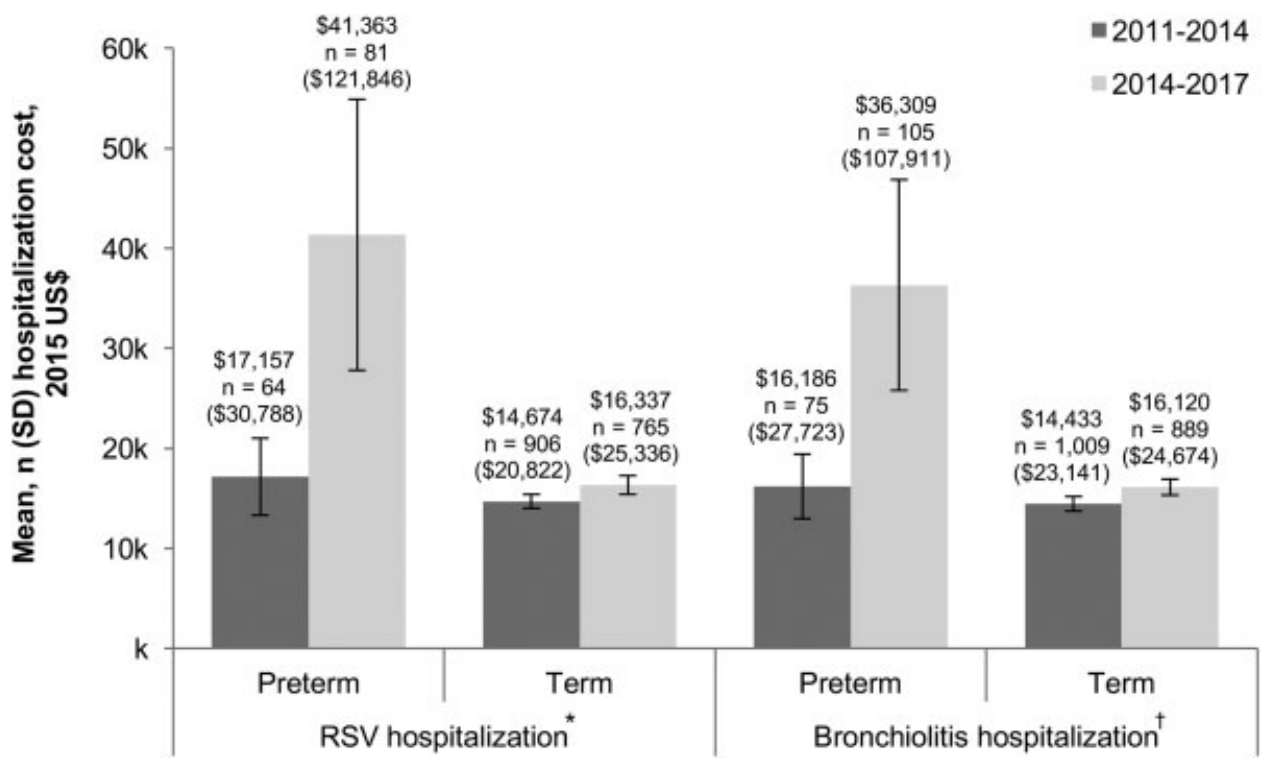

Fig. 5 Mean cost of RSV hospitalization and bronchiolitis hospitalization among infants with at least one hospitalization. Error bars represent \pm 1 standard error; $n$ values represent the number of hospitalizations. RSV, respiratory syncytial virus; SD, standard deviation. *Median (interquartile range) RSV hospitalization costs in 2011 to 2014 versus 2014 to 2017 were $\$ 10,742$ ( $\$ 18,682$ ) versus $\$ 14,179$ ( $\$ 18,682$ ) for preterm infants and $\$ 9,130(\$ 9,713)$ versus $\$ 10,164(\$ 11,171)$ for term infants. ${ }^{\dagger}$ Median (interquartile range) bronchiolitis hospitalization costs in 2011 to 2014 versus 2014 to 2017 were $\$ 9,151(\$ 10,906)$ and $\$ 12,823(\$ 18,841)$ for preterm infants and $\$ 9,044$ (\$9,165) versus $\$ 10,272(\$ 11,008)$ for term infants.

Previous studies have shown that RSVH is not only more common among younger infants ${ }^{1-3,5,8,30}$ but also more severe, with young preterm infants having the longest hospital stays and highest rates of ICU admission and mechanical ventilation use. ${ }^{5,8,9,32}$ For example, in the SENTINEL1 observational study of 29 to $35 \mathrm{wGA}$ infants aged $<12$ months who were hospitalized for RSV and did not receive RSV IP during the 2014 to 2015 RSV season, $42 \%$ of the overall study population had an ICU admission and 20\% required mechanical ventilation. ${ }^{5}$ Among infants aged $<3$ months, these percentages were 68 and $44 \%$, respectively. ${ }^{5}$ Younger infants and preterm infants have also been shown to have greater RSVH costs. ${ }^{5,22,32,33}$ Our results are congruent with these earlier findings and expand upon them by showing that RSVH severity among preterm infants increased after the AAP policy change. Similar observations were made in a retrospective study by Rajah et al, who found that several metrics of RSVH severity increased from the 2013 to 2014 season to the 2014 to 2015 season among 29 to 34 wGA infants aged $<3$ months, including ICU admission (from $30 \%$ to $68 \%$ ), use of mechanical ventilation (from $10 \%$ to $53 \%$ ), length of hospital stay (from 1.8 days to 8.8 days), and costs (from $\$ 19,686$ to $\$ 30,662$ ) ${ }^{9}$ Although cost increases were numerically greater for preterm versus term infants in our study, the relatively low number of preterm infants hospitalized for RSV or bronchiolitis likely contributed to lack of statistical significance for these differences from before to after the policy change. A possible explanation for increases in hospitalization severity and/or costs observed among preterm infants in our study and others is that infants hospitalized in 2014 to 2017 may have been at greater risk for more severe RSV disease because of reduced use of RSV IP among higher risk infants in 2014 to 2017 compared with 2011 to 2014. We found that the use of mechanical ventilation increased across both categories of infants in 2014 to 2017, although it remained more prevalent among preterm infants. This may have been due to the development of newer mechanical ventilation devices that are more efficient and easier to use, resulting in increased acceptance of noninvasive ventilation as a standard therapy for infants with bronchiolitis ${ }^{34}$ and decreased use of higher flow nasal cannula.

\section{Study Limitations}

This study has several limitations. As inpatient medication use is not captured by claims data, inpatient RSV IP (typically provided at discharge from the birth hospitalization during the RSV season) could not be examined. The proportion of infants who received RSV IP may therefore have been underestimated, both because some infants may have received it in the hospital, and because inpatient RSV IP may not have decreased to the extent seen for outpatient use because it is not usually subject to payer prior authorization. In addition, any claim for palivizumab was counted; information regarding the number and timing of doses per infant was not available, and doses were not required to be administered according to recommendations. It is possible that dosing as recommended would have resulted in a greater effect on the study outcomes. RSVH and BH were identified using ICD-9/ 10-CM diagnosis codes on inpatient claims because laboratory test results are not available in the claims database. Although RSV diagnosis codes have previously been shown to accurately reflect positive RSV test results in the emergency department setting, ${ }^{35}$ the number of RSVHs may be underestimated because the AAP does not recommend routine virologic testing, which could reduce the use of RSV diagnosis codes (although the effect of this limitation was mitigated by analyzing $\mathrm{BH}$ as well as RSVH). Similarly, 
identification of ICU admission and mechanical ventilation use may be suboptimal because of coding inconsistencies or undercoding due to bundling of inpatient hospitalization services. The low sample sizes of infants hospitalized for RSVH and BH may have contributed to an inability to detect statistical significance for some metrics of hospitalization severity and costs. Finally, as no required length of continuous health plan enrollment was specified, infants may have $<6$ months of follow-up, and RSVH or BH occurring after disenrollment would not have been captured.

\section{Conclusion}

The proportion of preterm infants receiving RSV IP decreased significantly after implementation of the more restrictive policy issued by the AAP COID in 2014. After this policy change, the already heightened risk of RSVH among preterm infants compared with term infants increased further, confirming the findings of other nationwide U.S. analyses. In addition to greater post-policy changes in RSV and BH rates for preterm infants, hospitalized infants experienced illnesses that were more severe, particularly for infants aged $<3$ months. These findings suggest that the youngest preterm infants are bearing a substantial burden from increased RSV-associated disease after the 2014 AAP policy change.

\section{Funding}

This study was supported by AstraZeneca (the manufacturer of palivizumab), which owned the U.S. rights to palivizumab at the time this work was completed. The U.S. rights to palivizumab are currently owned by Swedish Orphan Biovitrum AB.

\section{Conflict of Interest}

L.R.K. has received research funding from AstraZeneca. J.F. has served as a consultant for and on the speaker's bureau of AstraZeneca. M.G. has received grant/research support from AstraZeneca/MedImmune and served on the AstraZeneca Speaker's Bureau. L.B. is an employee of AstraZeneca and a shareholder in Sonic Healthcare (Sydney, Australia).

\section{Acknowledgments}

Medical writing services were provided by Yvette $M$. Edmonds, PhD, an employee of Optum (Eden Prairie, MN), which was in accordance with Good Publication Practice (GPP3) and was funded by AstraZeneca (Gaithersburg, MD). The authors thank Stephanie Korrer, MPH and Jeffrey T. McPheeters, BA (Optum) for data collection and analysis; and Tanya Burton, PhD (Optum) for assistance with study oversight.

\section{References}

1 Stockman LJ, Curns AT, Anderson LJ, Fischer-Langley G. Respiratory syncytial virus-associated hospitalizations among infants and young children in the United States, 1997-2006. Pediatr Infect Dis J 2012;31(01):5-9
2 Hall CB, Weinberg GA, Iwane MK, et al. The burden of respiratory syncytial virus infection in young children. N Engl J Med 2009;360 (06):588-598

3 Hall CB, Weinberg GA, Blumkin AK, et al. Respiratory syncytial virus-associated hospitalizations among children less than 24 months of age. Pediatrics 2013;132(02):e341-e348

4 American Academy of Pediatrics Committee on Infectious Diseases; American Academy of Pediatrics Bronchiolitis Guidelines Committee. Updated guidance for palivizumab prophylaxis among infants and young children at increased risk of hospitalization for respiratory syncytial virus infection. Pediatrics 2014; 134(02):415-420

5 Anderson EJ, Krilov LR, DeVincenzo JP, et al. SENTINEL1: an observational study of respiratory syncytial virus hospitalizations among U.S. infants born at 29 to 35 weeks' gestational age not receiving immunoprophylaxis. Am J Perinatol 2017;34(01): 51-61

6 Anderson EJ, Carbonell-Estrany X, Blanken M, et al. Burden of severe respiratory syncytial virus disease among 33-35 weeks' gestational age infants born during multiple respiratory syncytial virus seasons. Pediatr Infect Dis J 2017;36(02):160-167

7 García CG, Bhore R, Soriano-Fallas A, et al. Risk factors in children hospitalized with RSV bronchiolitis versus non-RSV bronchiolitis. Pediatrics 2010;126(06):e1453-e1460

8 Simões EA, Anderson EJ, Wu X, Ambrose CS. Effects of chronologic age and young child exposure on respiratory syncytial virus disease among US preterm infants born at 32 to 35 weeks gestation. PLoS One 2016;11(11):e0166226

9 Rajah B, Sánchez PJ, Garcia-Maurino C, Leber A, Ramilo O, Mejias A. Impact of the updated guidance for palivizumab prophylaxis against respiratory syncytial virus infection: a single center experience. J Pediatr 2017;181:183-188

10 The IMpact Study Group. Palivizumab, a humanized respiratory syncytial virus monoclonal antibody, reduces hospitalization from respiratory syncytial virus infection in high-risk infants. Pediatrics 1998;102(03):531-537

11 Synagis (palivizumab) [package insert]. Gaithersburg, MD: MedImmune; 2017

12 American Academy of Pediatrics Committee on Infectious Diseases and Committee on Fetus and Newborn. Prevention of respiratory syncytial virus infections: indications for the use of palivizumab and update on the use of RSV-IGIV. Pediatrics 1998; 102(05):1211-1216

13 Respiratory syncytial virus. In: Pickering LK, ed. Red Book: 2000 Report of the Committee on Infectious Diseases, 25th ed. Elk Grove Village, IL: American Academy of Pediatrics; 2000:483-487

14 Respiratory syncytial virus. In: Pickering LK, ed. Red Book: 2003 Report of the Committee on Infectious Diseases, 26th ed. Elk Grove Village, IL: American Academy of Pediatrics; 2003:523-528

15 Respiratory syncytial virus. In: Pickering LK, ed. Red Book: 2006 Report of the Committee on Infectious Diseases, 27th ed. Elk Grove Village, IL: American Academy of Pediatrics; 2006:560-566

16 Respiratory syncytial virus. In: Pickering LK, ed. Red Book: 2009 Report of the Committee on Infectious Diseases, 28th ed. Elk Grove Village, IL: American Academy of Pediatrics; 2009:560-569

17 Respiratory syncycital virus. In: Pickering LK, ed. Red Book: 2012 Report of the Committee on Infectious Diseases, 28th ed. Elk Grove Village, IL: American Academy of Pediatrics; 2012:609-618

18 Munoz FM, Ralston SL, Meissner HC. RSV recommendations unchanged after review of new data. AAP News; 2017

19 American Academy of Pediatrics Committee on Infectious Diseases; American Academy of Pediatrics Bronchiolitis Guidelines Committee. Updated guidance for palivizumab prophylaxis among infants and young children at increased risk of hospitalization for respiratory syncytial virus infection. Pediatrics 2014; 134(02):e620-e638

20 Kong AM, Krilov LR, Fergie J, et al. The 2014-2015 national impact of the 2014 American Academy of Pediatrics guidance for 
respiratory syncytial virus immunoprophylaxis on preterm infants born in the United States. Am J Perinatol 2018;35(02): 192-200

21 Blake SM, Tanaka D, Bendz LM, Staebler S, Brandon D. Evaluation of the financial and health burden of infants at risk for respiratory syncytial virus. Adv Neonatal Care 2017;17(04): 292-298

22 Goldstein M, Krilov LR, Fergie J, et al. Respiratory syncytial virus hospitalizations among U.S. preterm infants compared with term infants before and after the 2014 American Academy of Pediatrics guidance on immunoprophylaxis: 2012-2016. Am J Perinatol 2018;35(14):1433-1442

23 US Department of Labor, Bureau of Labor Statistics. Consumer Price Index. Medical Care. Series ID: SUUR0000SAM. Available at: http://data.bls.gov/cgi-bin/surveymost?su. Accessed April 23, 2018

24 Dimick JB, Ryan AM. Methods for evaluating changes in health care policy: the difference-in-differences approach. JAMA 2014; 312(22):2401-2402

25 Quick RD, Merkel K, Murphey DK, Fernandez M, Hauger SB. Impact of adopting 2014 guidance for palivizumab prophylaxis for children previously considered at high risk for severe respiratory syncytial virus disease. Int J Respir Pulm Med 2017;4(072)

26 Grindeland CJ, Mauriello CT, Leedahl DD, Richter LM, Meyer AC. Association between updated guideline-based palivizumab administration and hospitalizations for respiratory syncytial virus infections. Pediatr Infect Dis J 2016;35(07):728-732

27 Ambrose CS. Statistical power to detect an association between guideline-based palivizumab administration and hospitalizations for respiratory syncytial virus infections. Pediatr Infect Dis J 2017; 36(03):348

28 Farber HJ. Impact of the 2014 American Academy of Pediatrics guidance on respiratory syncytial virus and bronchiolitis hospitalization rates for infants born prematurely. J Pediatr 2017;185:250

29 Texas Medicaid/CHIP Vendor Drug Program Fee-for-Service Medicaid Synagis Request Form, 2014-2015 Season. Available at: http://www.maxor.com/forms/IVSolutions/pdfs/lubbock/synagis/SMN-Tx\%20Medicaid\%20Vendor\%20Drug\%20091614-IVSL. pdf. Accessed February 20, 2019

30 Boyce TG, Mellen BG, Mitchel EF Jr, Wright PF, Griffin MR. Rates of hospitalization for respiratory syncytial virus infection among children in Medicaid. J Pediatr 2000;137(06):865-870

31 Winterstein AG, Knox CA, Kubilis P, Hampp C. Appropriateness of age thresholds for respiratory syncytial virus immunoprophylaxis in moderate-preterm infants: a cohort study. JAMA Pediatr 2013; 167(12):1118-1124

32 Forbes ML, Hall CB, Jackson A, Masaquel AS, Mahadevia PJ. Comparative costs of hospitalisation among infants at high risk for respiratory syncytial virus lower respiratory tract infection during the first year of life. J Med Econ 2010;13(01):136-141

33 McLaurin KK, Farr AM, Wade SW, Diakun DR, Stewart DL. Respiratory syncytial virus hospitalization outcomes and costs of fullterm and preterm infants. J Perinatol 2016;36(11):990-996

34 Fedor KL. Noninvasive respiratory support in infants and children. Respir Care 2017;62(06):699-717

35 Makari D, Staat MA, Henrickson KJ, Wu X, Ambrose CS. The underrecognized burden of respiratory syncytial virus among infants presenting to US emergency departments. Clin Pediatr (Phila) 2015;54(06):594-597 